\title{
Evaluation of Effects of Oral Administration of Saffron Extract Combined with Moderate Aerobic Exercise on Glycemic Index and Lipid Profiles in Diabetic Rats
}

\author{
Roya Iraji ${ }^{1}$, Asghar Nikpoor ${ }^{1}$, Mohammad Ali Azarbayjani ${ }^{1 *}$, Maghsoud Peeri $^{1}$ and Mohammad Javad Rasaee ${ }^{2}$ \\ ${ }^{1}$ Department of Exercise Physiology, Islamic Azad University, Iran \\ ${ }^{2}$ Department of Clinical Biochemistry, Tarbiat Modares University, Iran
}

Submission: February 01, 2018; Published: September 21, 2018

*Corresponding author: Mohammad Ali Azarbayjani, Department of Exercise Physiology, Faculty of Physical Education and Sports Science, Tehran Central Branch, Islamic Azad University, Iranzamin St, Shahrake Gharb Sq, Tehran, Iran; Tel: +98-9123172908;

Email: m_azarbayjani@iauctb.ac.ir

\section{Abstract}

Introduction: Various methods have been studied for the prevention and treatment of diabetes. Medication, physical activity and diet are the most important. In the present study, we investigated hypoglycaemic and hypolipidemic effects of saffron extract in synergic with moderate aerobic exercise on diabetic rats.

Method: In an experimental trial, 42 Wistar rats were studied. Animals received single dose of streptozotocin $(60 \mathrm{mg} / \mathrm{kg})$ or citrate buffer solution (as the controls) intraperitoneally. Hyperglycaemia was observed in rats after 4 days. Rats were divided into five groups: the sham, diabetic control, diabetic with aerobic exercise, diabetic with saffron extract and combination of saffron extract and exercise. Blood samples were collected before and after two weeks of treatment, and plasma levels of glucose, insulin, cholesterol, triglycerides and free fatty acids were measured by the standard methods.

Results: Serum levels of glucose and cholesterol were significantly decreased in diabetic rats treated with saffron extract along with aerobic exercise compared to the diabetic control and sham. However, no change was observed in serum triglycerides, insulin, free fatty acids, and insulin resistance in any group.

Conclusion: The results of the present study suggest that consumption of saffron extract combined with moderate aerobic exercise may be useful for the prevention and treatment of Hyperglycemia and Hypercholesterolemia.

Keywords: Diabetes; Saffron extract; Glycemic index; Lipid profile

Abbreviations: FFT: Free Fatty Acids

\section{Introduction}

Diabetes mellitus is the most prevalent disease in developed and under developed countries and it is increasing sorely [1]. Global prevalence of diabetes is estimated to be 147 million in the year 2000, and it may involve 334 million people by 2025 [2]. Increasing prevalence of diabetes requires proper management for the control of the disease. Different therapeutic methods including medication, physical activity and diet have been used for the prevention and control of the disease. Aerobic exercise certainly affects the overall metabolism specially by decreasing blood glucose and lipids and so it has important therapeutic value [3]. Despite using moderate, regular exercise and diet for the management of diabetes mellitus, insulin and oral hyperglycemic drugs including Metformin, Glibanclamide and Thiazolidine have been used, which they have their own complications and adverse effects $[4,5]$. The results of one study showed that glibenclamide and metformin can be taken safely before postprandial exercise of moderate intensity without any side effect on cardiovascular, metabolic and hormonal responses. However, after moderate exercise these drugs prevent the normal rise in blood glucose and especially metformin delays the fall in plasma lactate concentrations [6].

There are continuing needs for a complementary and alternative medicine to control and prevent the disease. Commonly using herbs and other alternative therapies are less 


\section{Current Research in Diabetes \& Obesity Journal}

likely to have the side effects of conventional approaches for type 2 diabetes. For the same reason in recent years the attention has been focused on the use of medicinal plants.

In current study, we have used saffron (the highly consuming food flavour in most countries including Iran). Saffron is used in folk medicine for treatment of diabetes and its complications. Already various animal and human studies have suggested hypoglycemic and hypolipidemic effects of saffron and crocetin (one of original material in saffron) by different mechanisms such as increase of insulin sensitivity, insulin secretion by beta cells, decrease of lipid absorption, decrease in transmission of plasma lipoproteins [7-10]. Most research have showed consumption of saffron decreases glucose, triglyceride and total cholesterol $[7,8,11,12]$.

Different reports have indicated that regular and moderate aerobic exercise can make favourable changes in blood lipid profiles So that physicians recommend it for diabetic patients as an effective remedy. Inability of diabetic patients in performance of severs and long-term practice program is the limiting factor of this method. Thus, patients have to use other treatments such as pharmacotrapies to control disease complications. Because of side effects of drugs, today efforts are conducted to prevent and treat diseases without chemical drugs. Although the various studies have conducted to survey effects of saffron on decrease of blood glucose and improvement of lipid profile, combined effect of saffron and aerobic exercise is not clear. Aim of the present study is examination of saffron extract effects with low intensity aerobic exercise as a lipid and glucose decreasing factor on diabetes-related complications.

\section{Methods and Materials}

\section{Experimental animals}

Male wistar rats (No: 42, weight $=309.91 \pm 29.68$ ) were obtained from Animal Development and Maintenance Center at Razi Serum Institute of Iran. Animals were transferred to the animals keeping room at sport University of central Tehran, under standard laboratory conditions in a $12 \mathrm{~h} / 12 \mathrm{~h}$ light/ dark cycle and at a temperature of $22 \pm 2$ and the care taken for a period of 8 days, to get adapted to the place and conditions. Animals had free access to food and water. Rats were injected intraperitoneally with $60 \mathrm{mg} / \mathrm{kg}$ streptozotocin (From sigma company) dissolved in citrate buffer, on 8th day (after 12 hours fasting). The sham group have received citrate buffer solution at the same concentration. Four days after the injection, blood samples were collected from the rat's tail by pinching, and then assessed for blood glucose by glucometer. Rats whose blood glucose levels exceeded $200 \mathrm{mg} / \mathrm{dl}$ were entered to the experiment.

Animals were divided randomly into five groups: sham (control), diabetic control, diabetic with aerobic exercise, diabetic with saffron extract and diabetic with saffron and aerobic exercise.
1. The sham group $(n=7)$ : Normal rats who received citrate buffer solution equal to the volume of streptozotocin injected.

2. The diabetic control group $(n=10)$

3. The diabetic aerobic exercise group $(n=10)$ : Diabetic rats that participated in regular and low intensity physical training program for 2 weeks.

4. The diabetic saffron group $(n=10)$ : Diabetic rats that received daily $25 \mathrm{mg} / \mathrm{kg}$ hydro extract of saffron by gavage for 2 weeks.

5. The diabetic saffron and aerobic exercise group $(n=5)$ : Diabetic rats that received daily $25 \mathrm{mg} / \mathrm{kg}$ hydro extract of saffron by gavages for 2 weeks and participated in regular and low intensity physical training program.

\section{Preparation of saffron extract}

$9.2 \mathrm{gr}$ of saffron were poured in to $1000 \mathrm{ml}$ deionized water and mixed and incubated at $50^{\circ} \mathrm{C}$ for 16 hours. Then the solution was passed through filter paper and was kept at $4{ }^{\circ} \mathrm{C}$ during the usage.

\section{Exercise protocol}

Before the start of main experiment, animals were placed on a treadmill for a period of 5 days to get used to the instrument. During this period, the animals were running daily on a treadmill with a speed of $10 \mathrm{~m} / \mathrm{min}$ for 5 minutes. After the familiarization period main exercise was started. in the first week, animals were running on the treadmill with the slope of zero degree and speed of $10 \mathrm{~m} / \mathrm{min}$ for 5 days a week. In the second week, first animals were made to run 5 minutes at $10 \mathrm{~m} / \mathrm{min}$, and then the speed was increased to $12 \mathrm{~m} / \mathrm{min}$ and the training continued for more 10 minutes for 5 days a week. The exercise procedure was conducted at $4 \mathrm{pm}$ and the animals were stimulated to run by making sound, hitting their back and electric shock.

\section{Blood sampling and biochemical analyses}

Twenty hours after the experiment, finally animals were sacrificed. After the animals were anesthetized by chloroform (Merck Company), their chest was opened and approximately $5 \mathrm{ml}$ of blood was taken from the animal's heart. Blood samples were incubated for 10 minutes at room temperature until clotting, and then the tubes were centrifuged at $4000 \mathrm{rpm}$ for 20 minutes. The serum samples were kept at $-80{ }^{\circ} \mathrm{C}$ until the analysis. The glucose levels were measured by spectrophotometric method. Cholesterol and triglyceride were measured by enzymatic methods using commercial kits (Zist shimi and Pars Azmone, Iran), by an automatic analyzer (Abbott, model Alcyon 300, USA).

FFA was measured using kits of Gulf Bayrks Company. Serum insulin levels were assessed by ELISA method using insulin kit (DRG, international, Inc., USA). Insulin resistance was calculated by homeostasis model assessment (HOMA) [13]. 


\section{Current Research in Diabetes \& Obesity Journal}

\section{Statistical methods}

A one-way analysis of variance (ANOVA) and then Tukey test were used by SPSS software (version 17).

The values less than 0.05 were statistically significant.

Results

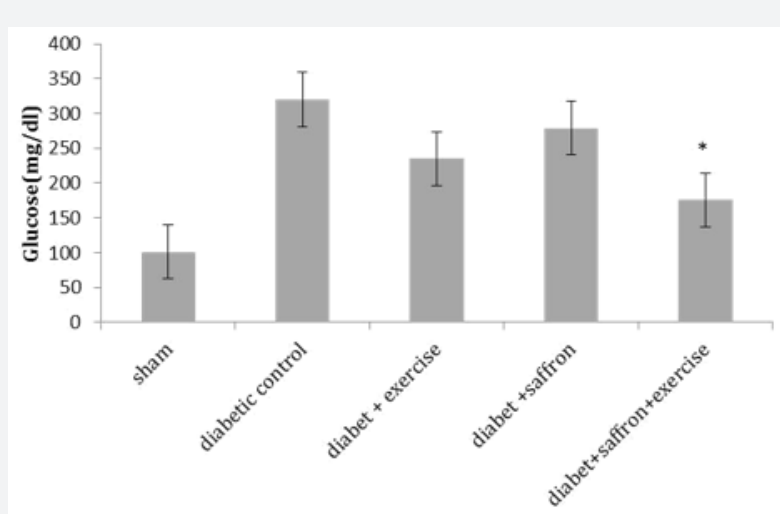

Figure 1: Comparison of serum glucose between the 5 groups: Data are presented based on mean standard deviation.

* shows significant different with diabetic control

Administration of STZ have increased significantly mean of serum glucose in diabetic control group compared with sham while treatment of animal with saffron extract and exercise lead to decrease in serum glucose mean in the diabetic saffron and aerobic exercise group compared with diabetic control (Figure 1).

Table 1: Statistical description of the mean concentrations of insulin insulin resistance and FFA participants in terms of distributional indicators.

\begin{tabular}{|c|c|c|c|}
\hline & Insulin $(\mathbf{p g} / \mathbf{m l})$ & $\begin{array}{c}\text { Insulin } \\
\text { Resistance }\end{array}$ & FFA (pg/ml) \\
\hline Sham & $150.57 \pm 40.74$ & $1.35 \pm 0.94$ & $0.52 \pm 0.02$ \\
\hline Diabetic control & $90.95 \pm 5.64$ & $1.97 \pm 0.75$ & $0.43 \pm 0.04$ \\
\hline $\begin{array}{c}\text { Diabetic aerobic } \\
\text { exercise }\end{array}$ & $111.95 \pm 48.59$ & $2.1 \pm 0.74$ & $0.46 \pm 0.05$ \\
\hline Diabetic saffron & $107.36 \pm 40.33$ & $2.61 \pm 0.61$ & $0.49 \pm 0.03$ \\
\hline $\begin{array}{c}\text { The diabetic } \\
\text { saffron and aerobic } \\
\text { exercise }\end{array}$ & $93.16 \pm 8.95$ & $2.53 \pm 1.26$ & $0.45 \pm 0.07$ \\
\hline
\end{tabular}

The STZ injection resulted in a significant decrease in serum insulin levels in diabetic control group compared to the sham group, but these values were not significantly different in the three treatment groups compared with diabetic control group. The mean of serum insulin concentrations in the diabeticexercised group was slightly higher than diabetic control group (Table 1). Insulin resistance in the diabetic aerobic exercise group, diabetic aerobic exercise group with saffron extract and diabetic saffron group showed no significant differences compared with the diabetic control group (Table 1).

STZ injection led to a slight decrease (but no significant) in mean of serum cholesterol in diabetic controls compared to sham. Also saffron in combination with aerobic exercise led to significantly lower mean serum cholesterol levels in diabetic aerobic exercise group with saffron extract compared with sham group (Figure 2).

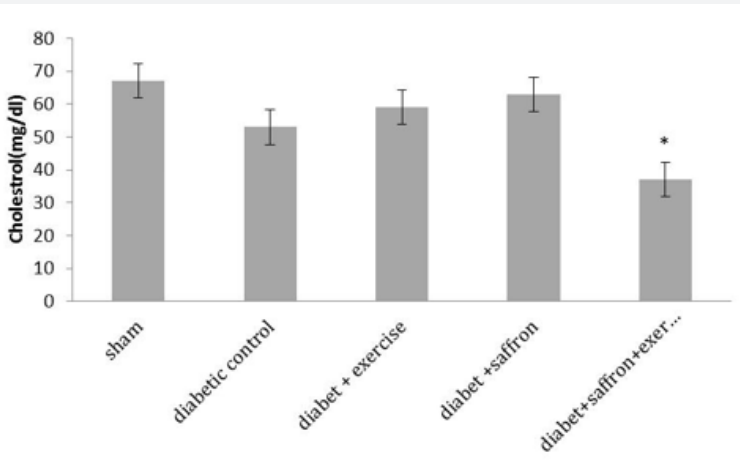

Figure 2: Comparison of serum cholesterol in 5 groups: Data are presented based on mean \pm standard deviation.

"shows significant different with sham

STZ injection led to a slight decrease (but no significant) in mean of serum triglyceride in diabetic controls compared to sham. Mean serum triglyceride levels were lower in three treatment groups (especially in diabetic aerobic exercise group with saffron extract) compared with diabetic control and sham groups but these differences were not statistically significant (Figure 3)

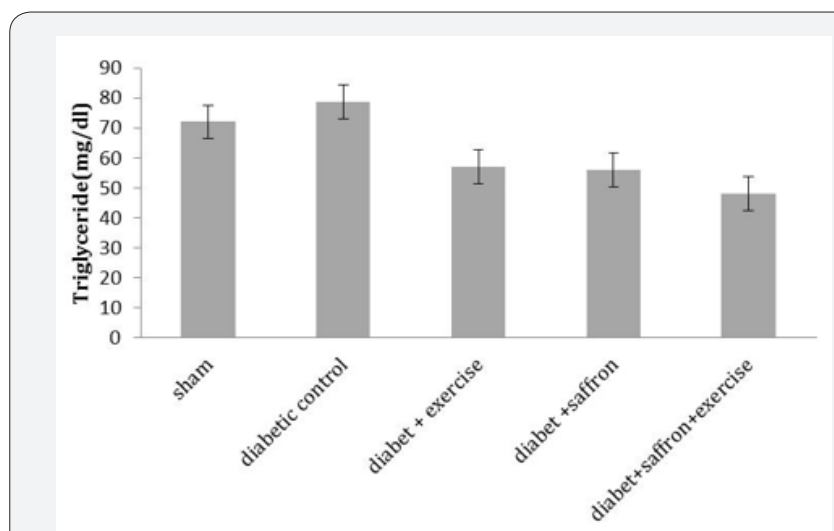

Figure 3: Comparison of serum triglycerides in 5 groups: Data are presented based on mean \pm standard deviation.

Average of serum FFA concentrations in diabetic control group was lower compared with the sham group and was higher slightly in all treatment groups but still mean levels were lower than the sham group. These differences were not statistically significant (Table 1).

\section{Discussion}

Diabetes is the most common metabolic disease in human that affect different organs in the body. Metabolic abnormalities in the are the characteristic of the disease [14].

Mean serum glucose concentrations in the aerobic exercise group with saffron extract were significantly lower compared 


\section{Current Research in Diabetes \& Obesity Journal}

with the diabetic control. Studies have proved that muscle contractions just like insulin action could decrease glucose level [15]. glucose is removed from blood by the activity of muscles independent of insulin action to maintain glycogen reserves [12]. Also, antioxidant compounds of plants can reduce the absorption of glucose in the intestine; this effect takes place probably by inhibiting digestive enzymes such as alpha glucosidase and alpha amilase, which are involved in carbohydrate hydrolysis, inhibition of transport of glucose from the folded membrane of small intestine and finally delay in emptying contents of stomach into the small intestine [16].

Crocetin administration improved insulin action, induced by high-fat diet in rats [17]. But in our study, the dose used was not able to make appropriate changes in plasma insulin levels. Hypertriglyceridemia is an important index in insulin resistance [18]. However, in the present study, despite the decrease in triglyceride levels, decline in insulin resistance was not seen. The lack of changes in insulin resistance could be due to the low dose Saffron and short duration of the exercise.

After two weeks of treatment, serum cholesterol levels in diabetic aerobic exercise group with saffron extract were significantly lower than the sham group. It has been reported that aerobic exercise can reduce blood cholesterol level $[19,20]$. This change is related to the intensity, duration and type of exercise $[19,20]$. Researchers believed this reduction is because of changes in regulatory enzymes and the increase in lipid utilization as fuel [3-21]. Also, a previous study has shown that Saffron consumption reducing blood cholesterol [8]. It seems Crocetin (contained in saffron) causes mal-absorption of fats and cholesterol and this is because of the crocetin effect in prevention of lipid hydrolysis through competition with pancreatic lipase. Also, crocetin increases excretion of cholesterol and fat in the stool while have no effect on bile acids [7]. According to the results, it seems combination of aerobic exercise and saffron can be very effective compared to saffron consumption alone because mean serum cholesterol levels was significantly lower in diabetic aerobic exercise group with saffron extract compared with diabetic saffron.

After the intervention period, mean serum triglyceride level was lower in three treatment groups compared with diabetic control but these differences were not statistically significant. This agrees with the report which indicates that aerobic exercise can reduce serum triglyceride level [19]. The intensity of activity and energy consumption during exercise is the main determining factor in this decline [20]. The mechanism of this effect could be due to short-term effects of aerobic exercise on lipid profile by changes in lipid regulating enzyme, lipoprotein lipase, Lecithin, cholesterol acyl transferase and hepatic triglyceride lipase [19]. Lipoprotein lipase increases utilization of triglycerides as fuel and enhances its removal from the blood even at rest [3]. It seems this effect is mediated through reduced secretion of triglyceride by the liver and increase in removal of triglyceride by muscle [20]. However, as mentioned, crocetin (present in saffron) decreases blood lipids by preventing hydrolysis of fats and increasing excretion of fats in faces [7]. It seems increase in duration of the period can cause significant effects on both serum triglycerides and cholesterol.

Plasma FFA levels increase significantly during aerobic exercise and this increment continues for hours after exercise [22]. However, in present study, due to the short duration of the activity, no change was seen in concentration of plasma FFA. Also, the previous studies have shown in human, crocetin attaches

to the fatty acid binding site in albumin molecule and limits transportation of fatty acids in plasma [9]. In the present study, oral administration of the extract had no effect on FFA levels in diabetic rats. This mechanism may be different in rats compared with humans and/or the consumption manner of saffron as oral or IV has a determining role in this factor. Finally, the treatment period did not change significantly plasma FFA levels in diabetic rats of saffron and aerobic exercise in comparison with the diabetic control group.

\section{Conclusion}

The results from present study showed that only glucose and cholesterol are sensitive to combination of low intensity aerobic activity and saffron extract and impressed by blend of two factors. This finding shows selective effect of the two interventions on glycaemic and lipid profile. In the other hand, since the combination of low intensity aerobic exercise and saffron extract reduces glucose and cholesterol more than each one alone, it can be concluded that aerobic exercise and saffron extract has a synergistic effect on blood glucose and cholesterol. Therefore, based on the findings from this study, the combination of light aerobic exercise and saffron extract can be an effective way to reduce glucose and cholesterol in diabetes. However, further studies are needed in this area.

\section{References}

1. Myśliwiec M, Balcerska A, Zorena K, Jędrzejczyk A, Malinowska E, et al (2007) Increasing Incidence of Diabetes Mellitus Type 1 in Childrenthe Role of Environmental Factors. Pol J Environ Stud 16(1): 109-112.

2. Wild S, Roglic G, Green A, Sicree R, King H (2004) Global prevalence of diabetes estimates for the year 2000 and projections for 2030 . Diabetes Care 27(5): 1047-1053.

3. Gudat U, Berger M, Lefebvre P, Bouchard C, Shephard R, et al. (1994) Physical activity, fitness, and non-insulin-dependent (type II) diabetes mellitus. Physical activity, fitness, and health international proceedings and consensus statement. Human Kinetics Publishers: 669-683.

4. Dey L, Attele AS, Yuan CS (2002) Alternative therapies for type 2 diabetes. Alternative medicine review. Altern Med Rev 7(1): 45-58.

5. Gilbert MP, Pratley RE (2009) Efficacy and safety of incretin-based therapies in patients with type 2 diabetes mellitus. Am J Med $122(6$ Suppl): S11-S24.

6. Cunha MR, da Silva ME, Machado HA, Fukui RT, Correa MR, et al. (2007) The effects of metformin and glibenclamide on glucose metabolism, counter-regulatory hormones and cardiovascular responses in women with Type 2 diabetes during exercise of moderate intensity. Diabetic medicine. Diabet Med 24(6): 592-599. 


\section{Current Research in Diabetes \& Obesity Journal}

7. Sheng L, Qian Z, Zheng S, Xi L (2006) Mechanism of hypolipidemic effect of crocin in rats: crocin inhibits pancreatic lipase. Eur J Pharmacol 543(1-3): 116-122.

8. Arasteh A, Aliyev A, Khamnei S, Delazar A, Mesgari M, et al. (2010) Effects of hydromethanolice extract of saffron (crocus sativus) on serum glucose, insulin resistance and cholesterol levels in healthy male rats. J Med Plant Res 4(5): 397-402.

9. Miller TL, Willett SL, Moss ME, Miller J, Belinka BA (1982) Binding of crocetin to plasma albumin. J Pharm Sci 71(2): 173-177.

10. Xi L, Qian Z, Xu G, Zheng S, Sun S, et al. (2007) Beneficial impact of crocetin, a carotenoid from saffron, on insulin sensitivity in fructosefed rats. J Nutr Biochem 18(1): 64-72.

11. Cousins JC, Miller Theodore L (1985) The Effects of Crocetin on Plasma Lipids in Rats. Ohio Journal of Science 85(3): 97-101.

12. Zheng S, Qian Z, Sheng L, Wen N (2006) Crocetin attenuates atherosclerosis in hyperlipidemic rabbits through inhibition of LDL oxidation. J Cardiovasc Pharmacol 47(1): 70-76.

13. Matthews DR, Hosker JP, Rudenski AS, Naylor BA, Treacher DF, et al. (1985) Homeostasis model assessment: insulin resistance and betacell function from fasting plasma glucose and insulin concentrations in man. Diabetologia 28(7): 412-419.

14. Davidson MB (2010) Diagnosis and Classification of Diabetes Mellitus. Diabetes Care 33(Suppl 1): S62-S69.

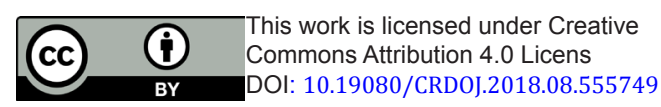

15. Bruce CR, Kriketos AD, Cooney GJ, Hawley JA (2004) Disassociation of muscle triglyceride content and insulin sensitivity after exercise training in patients with Type 2 diabetes. Diabetologia 47(1): 23-30.

16. Ashok K, Rao J (2002) Diabetes mellitus and multiple therapeutic of phytochemical: present status and future prospects. current science 83(1): 30-38.

17. Sheng L, Qian Z, Shi Y (2008) Crocetin improves the insulin resistance induced by high-fat diet in rats. Br J Pharmacol 154(5): 1016-1024.

18. Steiner G (1994) Hyperinsulinaemia and hypertriglyceridaemia. J Intern Med 736(Suppl): 23-26.

19. Press V, Freestone I, George C (2003) Physical activity: the evidence of benefit in the prevention of coronary heart disease. Qjm 96(4): 245251.

20. Katsanos CS (2006) Prescribing aerobic exercise for the regulation of postprandial lipid metabolism. Sports medicine 36(7): 547-560.

21. Manson JE, Nathan DM, Krolewski AS, Stampfer MJ, Willett WC, et al. (1992) A prospective study of exercise and incidence of diabetes among US male physicians. JAMA 268(1): 63-67.

22. Børsheim E, Knardahl S, Høstmark AT (1999) Short-term effects of exercise on plasma very low density lipoproteins (VLDL) and fatty acids. Med Sci Sports 31(4): 522-530.

\section{Your next submission with Juniper Publishers will reach you the below assets}

- Quality Editorial service

- Swift Peer Review

- Reprints availability

- E-prints Service

- Manuscript Podcast for convenient understanding

- Global attainment for your research

- Manuscript accessibility in different formats

( Pdf, E-pub, Full Text, Audio)

- Unceasing customer service

Track the below URL for one-step submission

https://juniperpublishers.com/online-submission.php 